\title{
PERANCANGAN SISTEM INFORMASI PENJUALAN ALAT ELEKTRONIK PADA SHOWROOM MASTER BERBASIS WEB
}

\section{FitriYunita}

ProgramStudiSistemInformasi, FakultasTeknikdan Ilmu Komputer UniversitasiIslamIndragiri(UNISI)

Jl. Propinsi,Parit1Tembilahan Hulu, Tembilahan, Riau, Indonesia

Email:fitriyun@gmail.com

\begin{abstract}
ABSTRAK
Showroom Master adalah sebuah perusahaan yang bergerak dibidang distribusi barang elektronik yang menyediakan beraneka jenis barang elektronik berbagai merk dengan kualitas yang bagus. Proses penjualan barang alat elektronik showroom master masih menggunakan media brosur yang mana membutuhkan biaya besar dan tidak efektif dalam melakukan pemasaran karena masih membutuhkan jasa untuk menyebarkan brosur tersebut kepada konsumen, dalam membuat laporan penjualan Showroom Master masih menggunakan cara yang rumit yaitu membutuhkan proses yang sangat lama dan semua laporan itu masih diinput menggunakan Microsoft Excel. Pembuatan desain laporan ini dianggap kurang tepat karena masih memiliki efek kesalahan yang besar dan lambat dalam melakukan pencatatan transaksi, hal ini berpengaruh pada pembuatan laporan sehingga laporan tersebut tidak tepat waktu. masalah media promosi, pengelolaan transaksi danpembuatan laporan tersebut membuat kegiatan kerja perusahaan menjadi sedikit terhambat terutama dibagian administrasi umum dan keuangan kerja di showroom Master.Untukmempermudah pihakperusahaan Showroom Master dalammengeloladatabarang elektronik, datatransaksi dan laporan, makaperludirancang sebuahsisteminformasipenjualan alat elektronik berbasis web. Dengan dibangunnyasisteminformasipenjualan eletronik berbasis webini,diharapkanmampumengatasipersoalanyangterjadi diShowroom Master,dapatmembantu memberikan laporandatatransaksipenjualansaat dibutuhkan, Memudahkan karyawan dalam melakukan promosi untuk pemasaran dansistem ini penyimpan data laporan transaksi lebih aman karena menggunakan database.
\end{abstract}

KataKunci:perancangan, sistem informasi elektronik, berbasis web. 


\section{PENDAHULUAN}

banyak bidang yang memanfaatkan sistem informasi berbasis komputer sebagai sarana untuk mempermudah pekerjaan, karena mampu menumbuhkan kinerja yang tinggi dan kinerja yang baik, maka akan saat mendukung pihak manajemen perusahaan dalam mengambil keputusan dan langkahlangkah, sehingga dapat mengurangi resiko kerugian atau bahkan dapat memperkecil pengeluaran biaya. Perusahaan merupakan tempat dalam mengelola sistem informasi. Hal ini terlihat banyaknya perusahaan menggunakan sistem komputerisasi untuk memperlancar aktivitas usahanya sehingga sistem manual sudah diminimalisasi.

Showroom Master adalah sebuah perusahaan yang bergerak dibidang distribusi barang elektronik yang menyediakan beraneka jenis barang elektronik berbagai merk dengan kualitas yang bagus. Proses penjualan barang alat elektronik showroom master masih menggunakan media brosur yang mana membutuhkan biaya besar dalam pembuatan brosur dan tidak efektif dalam melakukan pemasaran karena harus menyebarkan brosur kepada konsumen.Dalam membuat laporan penjualan masih menggunakan cara yang rumit yaitu order barang yang diterima oleh sales dan diprint menjadi surat jalan, setelah itu surat jalan akan diberikan kepada kepala perwakilan untuk disetujui setelah mendapat persetujuan surat jalan tersebut diberikan kepada kepala gudang, selanjutnya, kepala gudang akan memberikan surat jalan kepada sopir perusahaan, lalu barang yang dipesan pelanggan akan diantarkan oleh supir perusahaan. Semua laporan itu masih diinput menggunakan Microsoft Excel. Pembuatan laporan dianggap kurang tepat karena masih memiliki efek kesalahan yang besar dan lambat dalam melakukan pencatatan transaksi.Hal ini berpengaruh pada pembuatan laporan sehingga laporan tersebut tidak tepat waktu dan lambat. Masalah media promosi, pengelolaan transaksi danpembuatan laporan tersebut membuat kegiatan kerja perusahaan menjadi sedikit terhambat terutama dibagian administrasi umum, keuangan dan juga masalah bagi keefektifan kerja di showroom Master.

\section{Untukmempermudah}

pihakperusahaan Showroom Master dalammengeloladatabarang elektronik, datatransaksi dan laporan, makaperludirancang

sebuahsisteminformasipenjualan alat elektronik berbasis web. Dengan dibangunnyasisteminformasipenjualan

eletronik berbasis webini,diharapkanmampumengatasipersoala nyangterjadi diShowroom Master,dapatmembantu memberikan laporandatatransaksipenjualansaat dibutuhkan, Memudahkan karyawan dalam melakukan promosi untuk pemasaran dansistem ini penyimpan data laporan transaksi lebih aman karena menggunakan database.

\section{II.TINJAUANPUSTAKA \\ 2.1. Sistem}

Sistem adalah sekumpulan elemen yang saling terkait atau terpadu yang dimaksudkan untuk mencapai suatu tujuan (Kadir, 2014).

Setiap sistem meiliki elemen-elemen yang membentuk sistem tersebut, yaitu tujuan(goal), masukan(input), proses (process),keluaran(output), mekanisme pengendalian(controlmechanism) dan umpanbalik(feedback).

\subsection{Informasi}

Kadir, (2014) mendefinisikan informasi sebagai data yang telah diproses sedemikian rupa sehingga meningkatkan pengetahuan seseorang yang menggunakan data 


\subsection{Konsep Penjualan}

Pengertian penjualan menurut Kotler adalah sebuah proses dimana kebutuhan pembeli dan kebutuhan penjualan dipenuhi, melalui antar pertukaran informasi dan kepentingan. Jadi konsep penjualan adalah cara untuk mempengaruhi konsumen untuk membeli produk yang ditawarkan (Novera, 2014).

Pentingnya promosi penjualan karena promosi penjualan adalah kegiatankegiatan pemasaran selain personal selling, periklanan dan publisitas, yang mendorong efektivitas pembelian konsumen dan pedagang dengan menggunakan alat peragaan, pameran, demonstrasi dan sebagainya yang ditujukan untuk meningkatkan penjualan barang tertentu. Menurut Kotler, Dan Menurut Merle, pengukuran aktivitas penjualan adalah merupakan langkah awal untuk memaksimumkan produktivitasnya tenaga penjual, penjualan perusahaan diukur dari daerah yang dikuasainya, termasuk melakukan adopsi dari diri tenaga penjual.

Dalam meraih penjualan sudah barang tentu memerlukan suatu proses yang memang harus dirancang sebelumnya supaya hasilnya memuaskan, dibawah ini penulis tampilkan pula suatu skema proses penjualan.

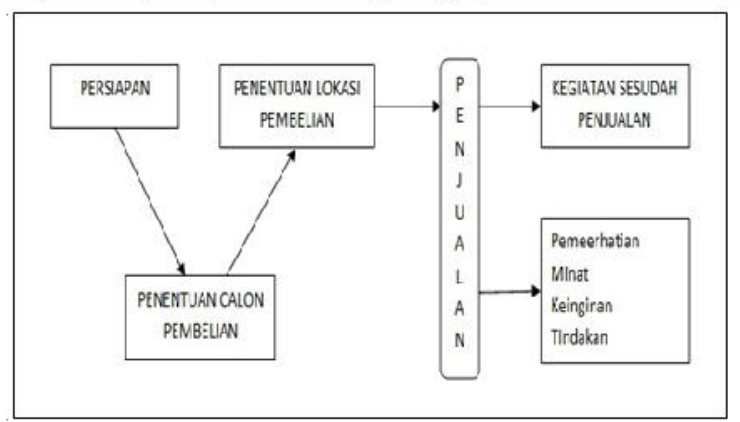

Gambar 1. Skema proses penjualan

\subsection{Konsep Pemodelan UML}

Unifield Modeling Language (UML) merupakan bahasa visual untuk pemodelan dan komunikasi mengenai sebuah sistem dengan menggunakan diagram dan teks-teks pendukung.UML hanya berfungsi untuk melakukan pemodelan.Jadi penggunaan UML tidak terbatas pada metodologi tertentu, meskipun pada kenyataannya UML paling banyak digunakan pada metodologi berorientasi objek.

\section{1) UseCaseDiagram}

Use Case Use case merupakan pemodelan untuk kelakuan (behavior) sistem informasi yang akan dibuat. Use case mendeskripsikan sebuah interaksi antara satu atau lebih aktor dengan sistem informasi yang akan dibuat. Secara kasar, Use case digunakan untuk mengetahui fungsi apa saja yang ada dalam sebuah sistem informasi dan siapa saja yang berhak menggunakan fungsi-fungsi itu (Rosa dan Shalahuddin, 2013).

Tiperelasiyangmungkinterjadipadause casediagram:

a $<$ include $>>$,yaitukelakuanyangharus terpenuhi agar sebuah event dapat terjadi,dimana padakondisiinisebuah usecaseadalahbagian dariusecase lainnya.

b $<$ extends $>>$, kelakuan yang hanya berjalan di bawah kondisi tertentu sepertimenggerakkanperingatan.

c $\quad<$ communicates $>>$, merupakanpilihan selamaasosiasihanya tiperelationship yangdibolehkan antaraaktordanuse case.

\section{2) Activiti Diagram}

Digram aktivitas atau Activity diagram menggambarkan workflow (aliran kerja) atau aktivitas dari sebuah sistem atau proses bisnis atau menu yang ada pada pereangkat lunak. Yang perlu diperhatikan disini adalah bahwa diagram aktivitas menggamarkan aktivitas sistem bukan apa yang dilakukan aktor, jadi akativitas yang dapat dilakukan oleh system 


\section{3) Class Diagram}

class diagram menggambarkan struktur sistem dari segi pendefinisian kelas kelas yang akan dibuat untuk membangun sistem.

a. Atribut merupakan variabel-variabel yang dimiliki oleh suatu kelas

b. Operasi atau metode adalah fungsi-fungsi yang dimiliki suatu kelas

\section{METODOLOGIPENELITIAN}

Metodepenelitianmerupakan cara atau teknik yang digunakan dalam rancangan bagunsisteminformasiini. Adapun metodeyangdiakukan dalam penelitianiniadalahsebagaiberikut:

\subsection{MetodeAnalisa Data}

Analisa dan perancangan sistem informasi penjualan pada Showroom Master ini dilakukan dengan menggunakan metode SDLC, yakni menggunakan model pengembangan waterfall. Gambar 2 merupakan bagan SDLC model waterfall yang umumnya terdiri dari 5 fase.

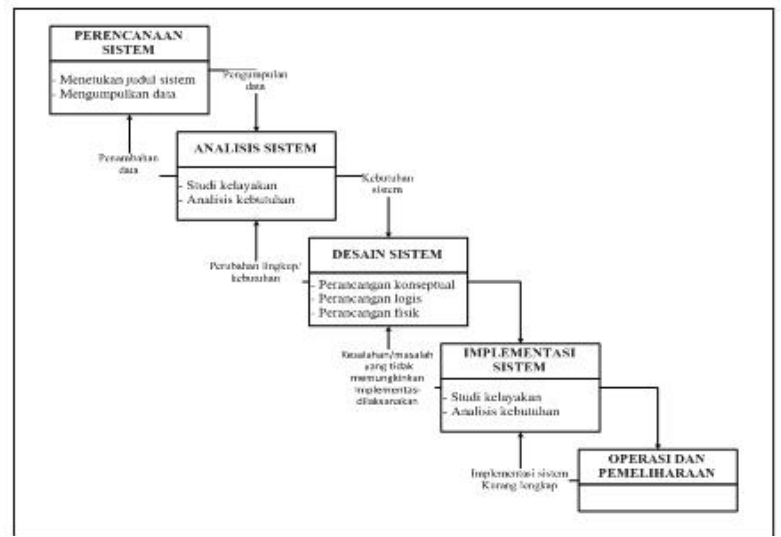

Gambar 2. Model Waterfall

\section{Analisa Sistem}

Analisa sistem digunakan untuk melihat dan menganalisa sistem yang akan dibagun pada Showroom Master. Apakah sistem tersebut layak untuk dikembangkan dan dibangun sistem informasi penjualan elektronik berbasis web.

2. Desain
Perancangan (design) ialah merancang sistem yang baru agar dapat digunakan untuk menyelesaikan permasalahan yang terjadi pada showroom Master, adapun desian sistem yang akan dibagun meliputi :

a. Desain Keluaran

Desain keluaran bertujuan untuk menentukan keluaran/output sistem informasi penjualan elektronik pada Showroom Master berbasis web.Keluaran tersebut berupa laporan.

b. Desain Masukan

Desain masukan bertujuan untuk menginputkan data masukan yang akan digunakan sebagai data yang akan diproses oleh sistem. Data masukan tersebut dapat berupa faktur, data transaksi dan data laporan barang masuk.

c. Desain File

Desain file dalam bagian perancangan basis data pada sistem informasi penjualan elektronik berbasis web ini dengan menggunakan pemodelan UML (Unified Modeling Language).

3. Implementasi

Implementasi menggambarkan tujuan untuk melakukan kegiatan spesifikasi dari rancanganlogical kedalam kegiatan yang sebenarnya dari sistem informasi penjualan elketronik pada showroom master berbasis web yang akan dibangun. Kemudian mengimplementasikan sistem yang baru tersebut kedalam bahasa pemograman.

\section{HASILDANPEMBAHASAN}

Tahap perancangan sistem informasi ini merupakan alat bantu untuk mendesain sistem baru yang akan dibuat, yang tujuannya adalah mengurangi kelemahan-kelemahan sistem dan mengatasi masalah-masalah yang terdapat pada pengelolaan data barag dan data penjualan di Showroom Master.

\subsection{Perancangan Proses}

Dalam perancangan proses ini, ada beberapa rancangan yang akan dipaparkan. 
Berikut ini adalah rancangan sistem secara umum yang diusulkan.

\section{a. Use Case Diagram}

Definisi actor pada perancangan sistem baru Showroom Master Tembilahan dijelaskan pada tabel berikut.

\section{Tabel 1. Definisi Aktor}

\begin{tabular}{|c|c|c|}
\hline No. & Actor & Deskripsi \\
\hline 1 & Pembeli & Membeli barang dan melihat barang \\
\hline 2 & $\begin{array}{l}\text { Karyawan Bagıan } \\
\text { Marketing }\end{array}$ & $\begin{array}{l}\text { Melayan pembelı. Membantu pembeli/kcnsumen } \\
\text { menemukan barang yang dicari }\end{array}$ \\
\hline No. & $\begin{array}{l}\text { Actor } \\
\text { ADM }\end{array}$ & $\begin{array}{l}\text { Deskripsi } \\
\text { Bertugas mengelo.a data penjualan sapeti entri } \\
\text { data barang masuk dan membuat laporan. }\end{array}$ \\
\hline 4 & Pimpinan & Menerima laporan dari ADM Showroom \\
\hline
\end{tabular}

Use Case adalah bentuk gambaran umum sistem yang akan dibuat pada sistem informasi showroom master berbasis web. Gambaran Use Casediagram dapat dilihat pada gambar 3 .

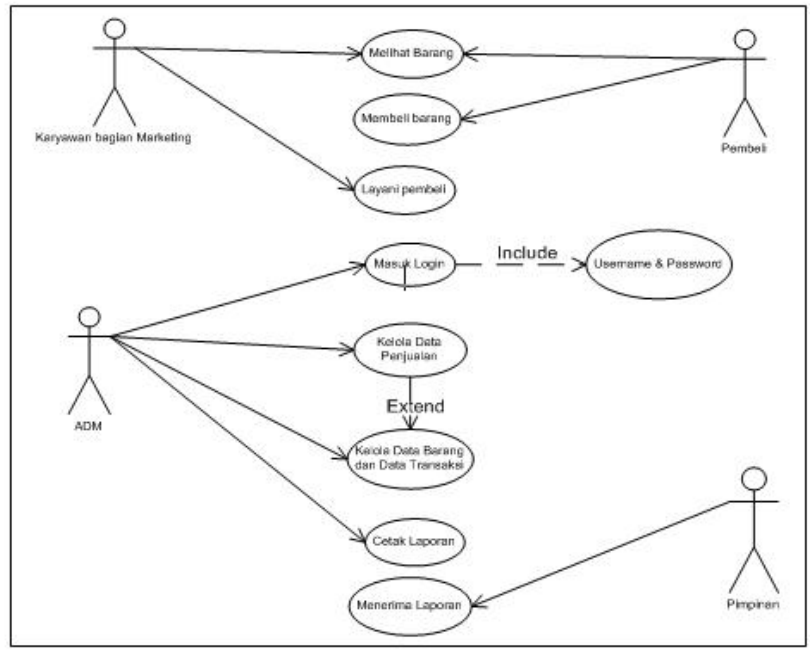

Gambar 3. Use Case Diagram

Diagram Use Case di atas menggambarkan sistem informasi penjualan elektonik berbasis websecara keseluruhan pada Showroom Master.Pada sistem ini, aktivitas-aktivitas yang terjadi pada sistem penjualan digambarkan dengan Use Case, kemudian sebagai pelakunya digambarkan dengan actor.

\section{b. Activity Diagram}

Activity diagram menggambarkan proses perangkat lunak sebagai aliran kerja melalui serangkaian tindakan yang terjadi pada sisitem informasi penjualan elektronik berbasis web pada showroom master.

Bentuk diagram aktivitas login pada sistem informasi penjualan Alat Elektronik dapat dilihat pada gambar 4 berikut ini.

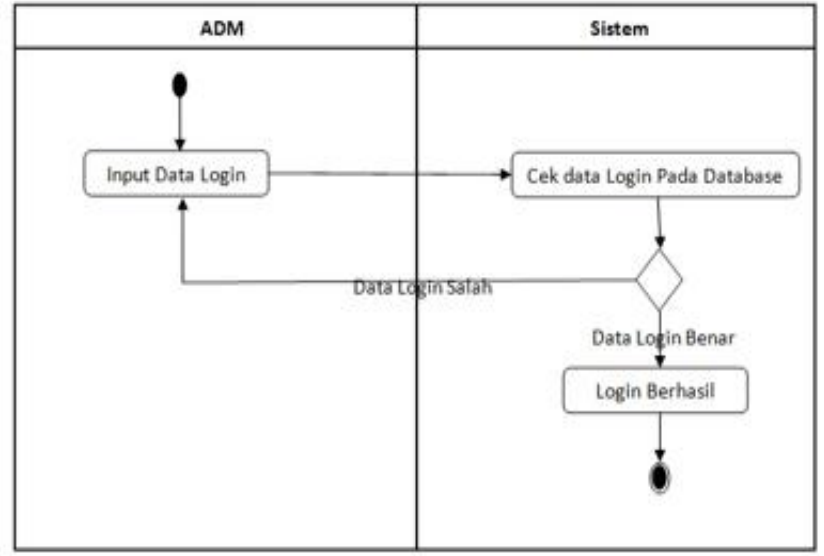

\section{Gambar 4. Diagram Aktiviti Login}

Pada aktivitas login dimulai dengan memasukkan data login, yaitu username dan password. Kemudian sistem akan melakukan validasi data. Apabila terjadi kesalahan dalam memasukkan login, maka sistem akan menampilkan pesan kesalahan dan meminta pengguna memasukkan kembali username dan passwordyang benar. Apabila data login sudah benar, maka sistem akan menampilan menu utama yang terdapat pada halaman web.

Bentuk diagram aktivitas input data barang pada sistem informasi penjualan alat elektronik showroom master dapat dilihat pada gambar 5 berikut ini. 


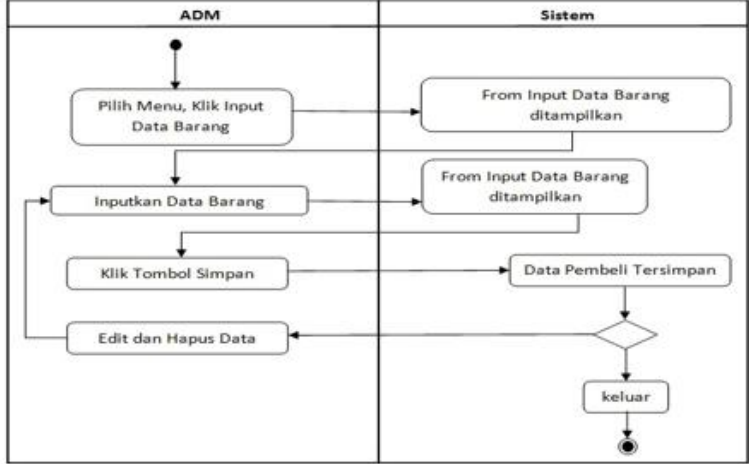

Gambar 5. Diagram Aktiviti Input Data Barang

Aktivitas input data barang dimulai dengan memilih menu data yang terdapat pada menu data barang, klik barang, kemudian sistem akan menampilkan form input data barang, setelahform barang ditampilakan, baru admin bisa menginputkan data barang dan kemudian klik tombol simpan maka data akan tersimpan.

Bentuk diagram cetak laporan pada sistem informasi penjualan alat elektronik Showroom Master dapat dilihat pada gambar 6 berikut ini.

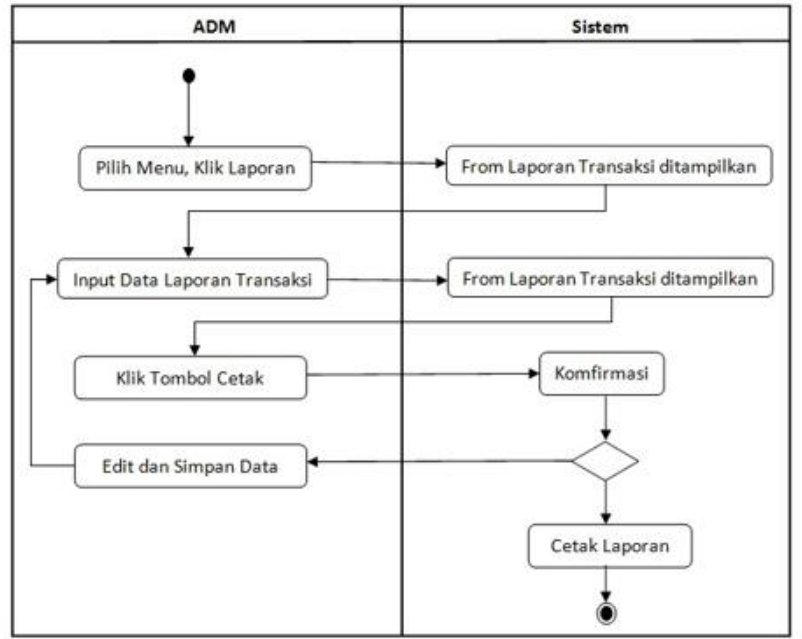

Gambar 6. Diagram Aktiviti Cetak Laporan

Aktivitas mencetak laporan dimulai dengan memilih menu dengan klik laporan, kemudian sistem akan menampilkan form interface/antarmuka. Admin memilih laporan bulan atapun tahunan apa yang akan ditampilkan, kemudian admin akan mengkonfirmasinya dengan mengklik tombol ok. Sistem akan menunggu perintah cetak laporan dari admin. Apabila admin telah konfrimasi cetak, sistem akan mencetak laporan.

\section{c. Class Diagram}

Bentuk Diagram Class saat Aktivitas dalam Diagram Class Saling terhubung dengan satu dengan yang lainnya. Seperti gambar 7 dibawah.

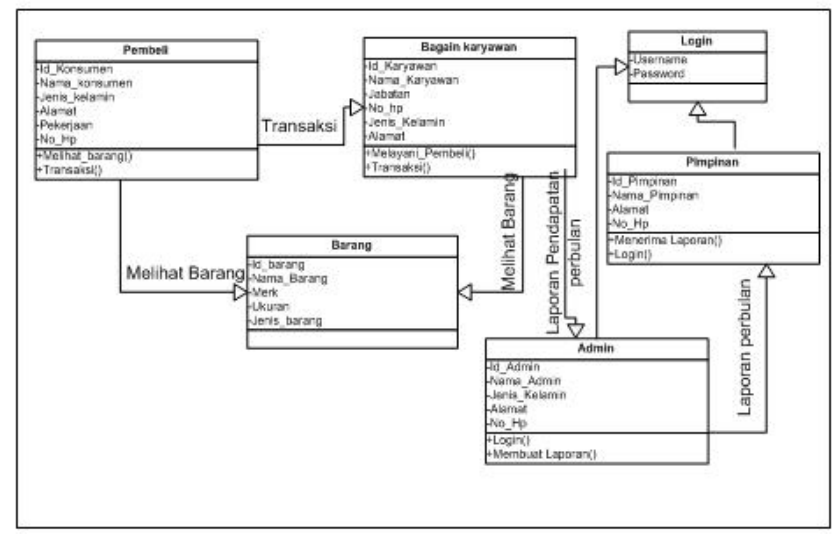

\section{Gambar 7.Class Diagram}

Aktivitas yang terjadi di class diagram dimulai dari konsumen melihat barang yang sesuai dengan kenginannya. Setelah konsumen memilih barang maka bagian penjualan/sales dan melakukan transaksi dengan konsumen sampai transaksi disetujui oleh kedua belah pihak.Setelah bagian penjualan/sales selesai melakukan transaksi dengan konsumen, bagian penjualan/sales memberikan laporan pendapatan kepada admin agar nanti saat membuat laporan admin tidak lagi harus mencari laporan pendapatan.Setelah admin selesai membuat laporan, laporan tersebut diprint/cetak dan diterima oleh pimpinan untuk disimpan.

\subsection{Implementasi}

tersebut dibuat sesuai dengan desainnya dan menghasilkan tampilan sesuai kebutuhan pemakai sistem.Tujuan dari pengujian sistem ini adalah :

1. Untuk mengetahui apakah sistem yang dibuat memudahkan dan sesuai dengan kebutuhan pengguna.

2. Untuk mengetahui apakah tampilan yang disajikan cukup menarik 
3. Apakah tombol-tombol berfungsi dengan baik dan sesuai harapan

\section{Halaman Menu Utama}

Menu utama adalah menu awal yang langsung dapat dilihat apabila kita menjalankan aplikasi tersebut, dan ada 7 tombol yang merupakan menu-menu dari $W e b$. Yaitu Home, Tentang Kami, Sejarah, Kisaran Harga, Visi dan Misi, Hubungi Kami dan Keluar.

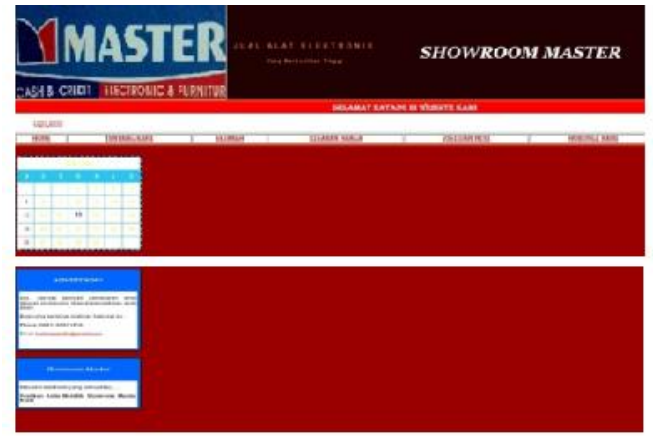

Gambar 8. Halaman Menu Utama

\section{Halaman Login Admin}

Form login admin dalam merupakan langkah utama untuk masuk kedalam halaman menu admin dan bertindak sebagai pengaman aplikasi, agar aplikasi sistem penjualan elektronik ini tidak bisa diakses oleh pihak yang tidak berhak, maka setiap pengguna harus memaskanusename dan password untuk masuk kesistem admin.

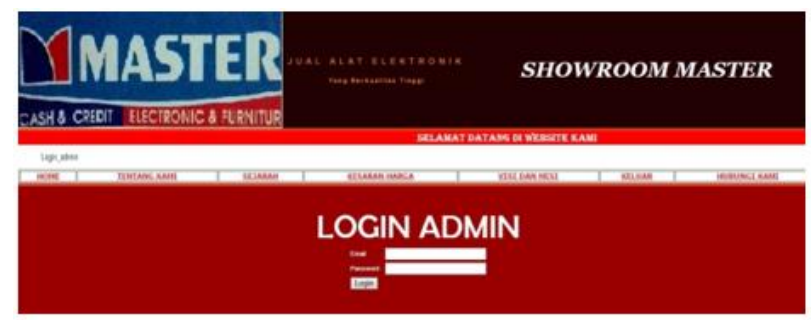

Gambar 9. Halaman Login Admin

\section{Halaman Menu Admin}

Menu Admin adalah menu admin yang hanya dapat dilihat apabila kita sudah mamasukkan username dan password pada login admin tersebut, dan ada beberapa menu yang terdapat dalam web ini antara lain. Yaitu Input Data Barang, Input Data Pembeli, Laporan dan Keluar.

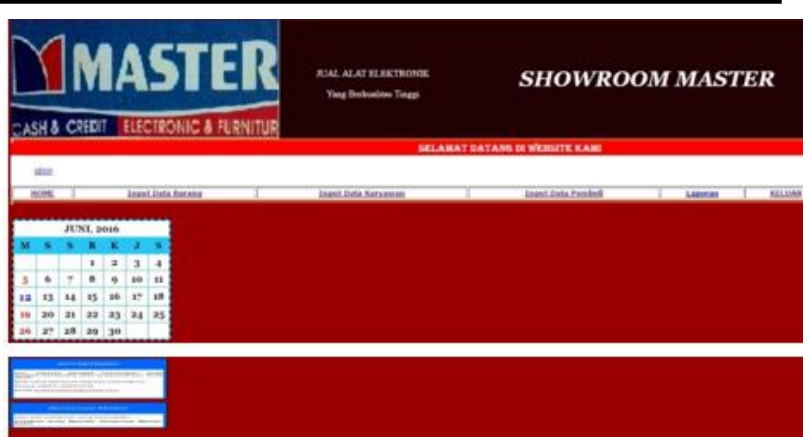

Gambar 10. Halaman Menu Admin

\section{Halaman Input Data Barang}

Form data barang dalam aplikasi ini merupakan sistem yang digunakan untuk menyimpan, edit dan hapus data barang ketika terjadi barang akan masuk dan stok barang berkurang digudang. Data barang yang sudah di inputkan akan tersimpan didalam database. Aplikasi ini tidak bisa diakses oleh pihak yang tidak berhak, maka setiap pengguna harus entri usename dan password untuk masuk kesistem admin.
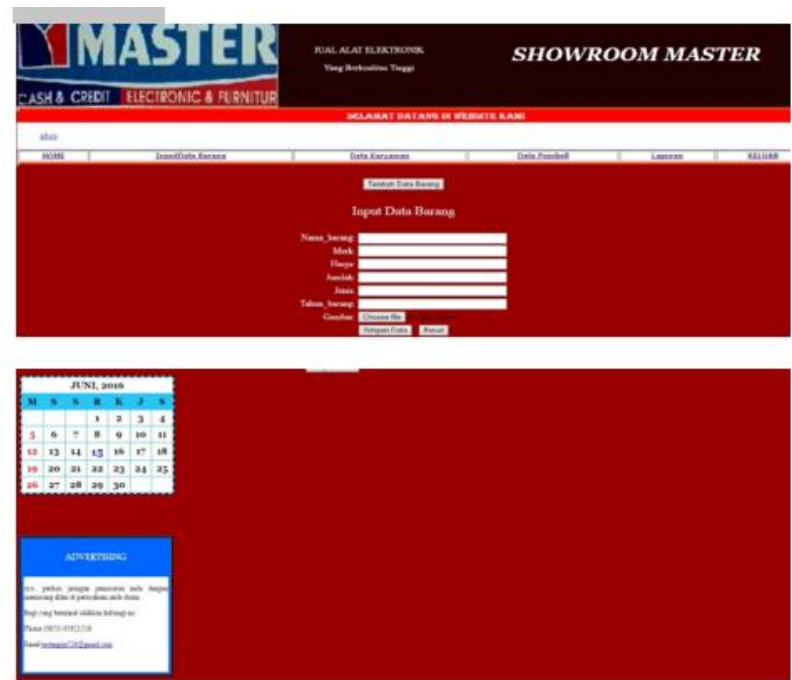

Gambar 11. Halaman Input data Barang

\section{Halaman Input Data Pembeli}

Form input data pembelidalam aplikasi ini merupakan sistem yang digunakan untuk menyimpan, edit dan hapus data pembeli ketika sudah selesai melakukan transaksi antara pembeli dan karyawan. Data barang yang sudah di inputkan akan tersimpan didalam database. 


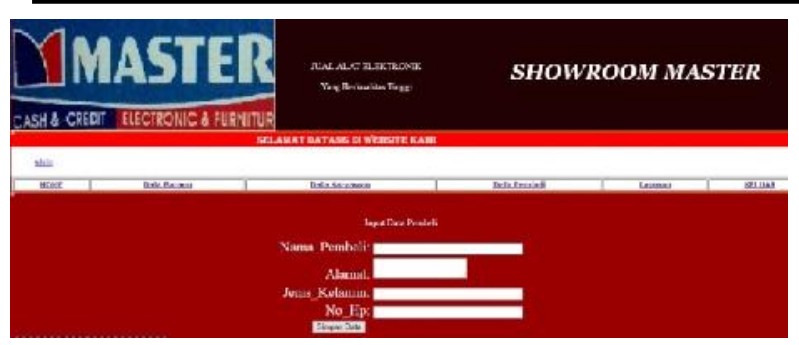

Gambar 12. Halaman Input data Pembeli

\section{Halaman Laporan Transaksi}

Form input laporan transaksi dalam aplikasi ini merupakan sistem yang digunakan untuk menginputkan laporan akhir bulan selama transaksi yang sudah terjadi. Data laporan transaksi yang sudah di inputkan akan tersimpan didalam database.

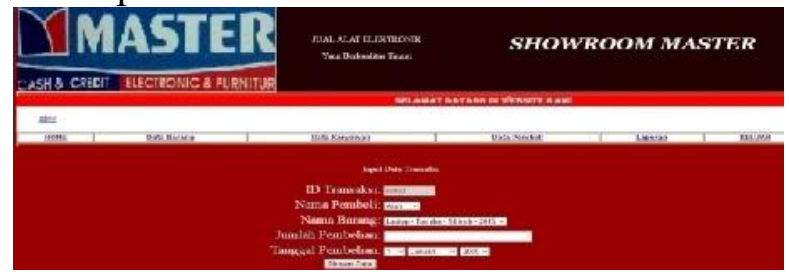

Gambar 13. Halaman Laporan Transaksi

\section{Halaman Output Laporan}

Hasil output laporan merupakan hasil akhir dimana setelah menginputkan laporan transaksi dan akan ingin dicetak/print hasilnya seperti Gambar dibawah ini :

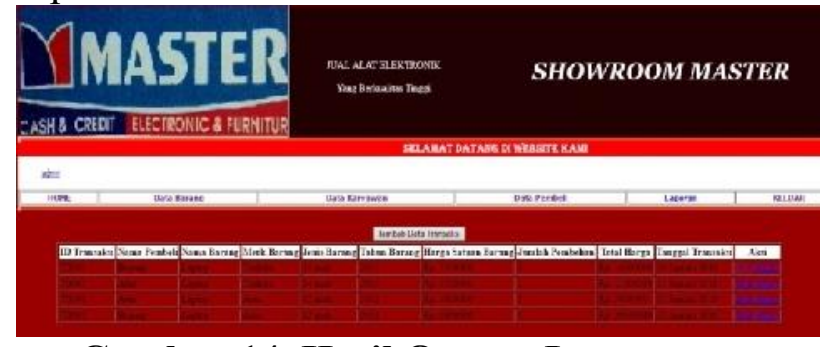

Gambar 14. Hasil Output Laporan

\subsection{Pengujian Sistem}

Pengujian yang dilakukan secara objektif, yaitu dengan menguji langsung terhadap para karyawan yang bekerja di Showroom Master yang akan diterapkan, dengan membuat kuesioner mengenai kepuasan pengguna terhadap Web yang dibuat. Hasil pengujiannya sebagai berikut :

1. Menurut anda, apakah Web penjualan Showroom Master ini mudah digunakanuntuk admin?
Tabel 2. Hasil Pengujian Kuesioner Soal Nomor 1

\begin{tabular}{|c|c|c|c|c|}
\hline $\begin{array}{c}\text { Pertan } \\
\text { yaan }\end{array}$ & $\begin{array}{c}\text { Skala } \\
(\mathbf{N})\end{array}$ & $\begin{array}{c}\text { Ketera } \\
\text { ngan }\end{array}$ & $\begin{array}{c}\text { Responde } \\
\mathbf{n}(\mathbf{R})\end{array}$ & $\begin{array}{c}\mathbf{N x} \\
\mathbf{R}\end{array}$ \\
\hline \multirow{5}{*}{1} & 5 & $\begin{array}{l}\text { Sangat } \\
\text { Mudah }\end{array}$ & 10 & 50 \\
\hline & 4 & Mudah & 0 & 0 \\
\hline & 3 & $\begin{array}{l}\text { Cukup } \\
\text { Mudah }\end{array}$ & 0 & 0 \\
\hline & 2 & $\begin{array}{l}\text { Kurang } \\
\text { Mudah }\end{array}$ & 0 & 0 \\
\hline & 1 & $\begin{array}{l}\text { Tidak } \\
\text { Mudah }\end{array}$ & 0 & 0 \\
\hline & 10 & 40 \\
\hline
\end{tabular}

Berdasarkan hasil persentase tersebut, maka dapat disimpulkan bahwa pengguna cenderung diantara sangat Mudah dalam penggunaan dan terbantu dengan adanyaweb penjualan Showroom Master ini, berikut kriteria interprestasi skor:

$$
y=\frac{50}{50} \times 100 \%=100 \%
$$

2. Menurutanda,apakahWeb penjualan Showroom Master ini membantu anda dalam mengembangkan media promosi pemasaran yang lebih menarik ?

Tabel 3. Hasil Pengujian Kuesioner Soal Nomor 2

\begin{tabular}{|c|c|l|c|c|}
\hline $\begin{array}{c}\text { Pertan } \\
\text { yaan }\end{array}$ & $\begin{array}{c}\text { Skala } \\
\text { (N) }\end{array}$ & $\begin{array}{l}\text { Ketera } \\
\text { ngan }\end{array}$ & $\begin{array}{c}\text { Responde } \\
\text { n(R) }\end{array}$ & $\begin{array}{c}\text { Nx } \\
\text { R }\end{array}$ \\
\hline \multirow{2}{*}{2} & 5 & $\begin{array}{l}\text { Sangat } \\
\text { Memba } \\
\text { ntu }\end{array}$ & 1 & 5 \\
\cline { 2 - 5 } & 4 & $\begin{array}{l}\text { Memba } \\
\text { ntu }\end{array}$ & 8 & 32 \\
\cline { 2 - 5 } & 3 & $\begin{array}{l}\text { Cukup } \\
\text { Memba } \\
\text { ntu }\end{array}$ & 1 & 3 \\
\cline { 2 - 5 } & 2 & $\begin{array}{l}\text { Kurang } \\
\text { Memba } \\
\text { ntu }\end{array}$ & & \\
\hline
\end{tabular}




\begin{tabular}{|l|l|l|l|l|}
\hline & 1 & $\begin{array}{l}\text { Tidak } \\
\text { Memba } \\
\text { ntu }\end{array}$ & & \\
\hline Jumlah & & & 40 \\
\hline
\end{tabular}

Berdasarkan hasil persentase tersebut, maka dapat disimpulkan bahwa pengguna cenderung diantara banyak memilih membantu dari pada sangat membantu dan cukup membantu dalam penggunaan Web penjualan Showroom Master ini, berikut kriteria interprestasi skor:

$$
y=\frac{40}{50} \times 100 \%=80 \%
$$

3. Menurutanda,apakahWeb penjualan Showroom Master ini membantu menarik minat pembeli

Tabel 4. Hasil Pengujian Kuesioner Soal Nomor 3

\begin{tabular}{|c|c|l|c|c|}
\hline $\begin{array}{c}\text { Pertany } \\
\text { aan }\end{array}$ & $\begin{array}{c}\text { Skala } \\
(\mathbf{N})\end{array}$ & $\begin{array}{l}\text { Keteran } \\
\text { gan }\end{array}$ & $\begin{array}{c}\text { Responde } \\
\text { n(R) }\end{array}$ & $\begin{array}{c}\text { Nx } \\
\mathbf{R}\end{array}$ \\
\hline \multirow{4}{*}{3} & 5 & $\begin{array}{l}\text { Sangat } \\
\text { Memban } \\
\text { tu }\end{array}$ & 1 & 5 \\
\cline { 2 - 5 } & 4 & $\begin{array}{l}\text { Memban } \\
\text { tu }\end{array}$ & 6 & 24 \\
\cline { 2 - 5 } & 3 & $\begin{array}{l}\text { Cukup } \\
\text { Memban } \\
\text { tu }\end{array}$ & 3 & 9 \\
\cline { 2 - 5 } & 2 & $\begin{array}{l}\text { Kurang } \\
\text { Memban } \\
\text { tu }\end{array}$ & $\begin{array}{l}\text { Tidak } \\
\text { Memban } \\
\text { tu }\end{array}$ & \\
\hline Jumlah & 1 & & 38 \\
\hline
\end{tabular}

Berdasarkan hasil persentase tersebut, maka dapat disimpulkan bahwa pengguna cenderung diantara sangat membantu, membantu dan cukup membantu dalam penggunaan Web penjualan Showroom Master ini, berikut kriteria interprestasi skor:

$$
y=\frac{38}{50} \times 100 \%=76 \%
$$

4. Menurutanda,apakahWeb penjualan Showroom Master ini membantu anda dalam bekerja?

Tabel 5. Hasil Pengujian Kuesioner Soal

\begin{tabular}{|c|c|c|c|c|}
\hline $\begin{array}{c}\text { Pertan } \\
\text { yaan }\end{array}$ & $\begin{array}{c}\text { Skala } \\
(\mathbf{N})\end{array}$ & $\begin{array}{c}\text { Ketera } \\
\text { ngan }\end{array}$ & $\begin{array}{c}\text { Responde } \\
\mathbf{n}(\mathbf{R})\end{array}$ & $\begin{array}{c}\mathbf{N x} \\
\mathbf{R}\end{array}$ \\
\hline \multirow{5}{*}{4} & 5 & $\begin{array}{l}\text { Sangat } \\
\text { Memba } \\
\text { ntu }\end{array}$ & 1 & 5 \\
\hline & 4 & $\begin{array}{l}\text { Memba } \\
\text { ntu }\end{array}$ & 7 & 28 \\
\hline & 3 & $\begin{array}{l}\text { Cukup } \\
\text { Memba } \\
\text { ntu }\end{array}$ & 2 & 6 \\
\hline & 2 & $\begin{array}{l}\text { Kurang } \\
\text { Memba } \\
\text { ntu }\end{array}$ & & \\
\hline & 1 & $\begin{array}{l}\text { Tidak } \\
\text { Memba } \\
\text { ntu }\end{array}$ & & \\
\hline \multicolumn{3}{|l|}{ Jumlah } & & 39 \\
\hline
\end{tabular}
Nomor 4

Berdasarkan hasil persentase tersebut, maka dapat disimpulkan bahwa pengguna cenderung diantara sangat membantu, membantu dan cukup membantu dalam penggunaan Web penjualan Showroom Master, berikut kriteria interprestasi skor:

$$
y=\frac{39}{50} \times 100 \%=78 \%
$$

5. Menurutanda,apakahWeb penjualan Showroom Master ini menarik untuk digunakanAdmin?

Tabel 6. Hasil Pengujian Kuesioner Soal Nomor 5

\begin{tabular}{|c|c|l|c|c|}
\hline $\begin{array}{c}\text { Pertan } \\
\text { yaan }\end{array}$ & $\begin{array}{c}\text { Skal } \\
\mathbf{a ( N )}\end{array}$ & $\begin{array}{c}\text { Keteran } \\
\text { gan }\end{array}$ & $\begin{array}{c}\text { Respond } \\
\text { en(R) }\end{array}$ & $\begin{array}{c}\mathbf{N x} \\
\mathbf{R}\end{array}$ \\
\hline \multirow{3}{*}{5} & 5 & $\begin{array}{l}\text { Sangat } \\
\text { Menarik }\end{array}$ & & \\
\cline { 2 - 5 } & 4 & Menarik & 3 & 12 \\
\cline { 2 - 5 } & 3 & $\begin{array}{l}\text { Cukup } \\
\text { Menarik }\end{array}$ & 7 & 21 \\
\hline
\end{tabular}




\begin{tabular}{|l|c|l|l|l|}
\hline & 2 & $\begin{array}{l}\text { Kurang } \\
\text { Menarik }\end{array}$ & & \\
\cline { 2 - 5 } & 1 & $\begin{array}{l}\text { Tidak } \\
\text { Menarik }\end{array}$ & & \\
\hline Jumlah & & 33 \\
\hline
\end{tabular}

Berdasarkan hasil persentase tersebut, maka dapat disimpulkan bahwa pengguna cenderung diantara menarik dan cukup menarik dalam penggunaan Web penjualan Showroom Master, berikut kriteria interprestasi skor:

$$
y=\frac{33}{50} \times 100 \%=66 \%
$$

\section{PENUTUP}

\subsection{Kesimpulan}

Berdasarkanhasilpenelitianyang telah dilakukan, kesimpulan dari penelitian ini adalahsebagaiberikut:

1. Sistem informasi penjualan Showroom Master ini menggunakan database yang telah terprogram sehingga jika diperlukan kembali data laporan transaksi para karyawan bisa mencari didatabase.

2. Sistem ini juga bisa sebagai media promosi pemasaran agar pemasaran Showroom Master lebih luas dengan persentasi 80\%.

3. Sistem Penjualan berbasis web ini juga memudahkan admin dalam membuat laporan transaksi dengan persentasi $100 \%$

\subsection{Saran}

Adapun untuk perancangan kedapannya sistem penjualan agar lebih luas lagi tidak hanya dalam transaksi penjualan, laporan dan juga media promosi tetapi juga sistem penjualan bisa membuat menu lainnya seperti menu barang yang diskon dan lain sebagainnya.

\section{REFERENSI}

Kadir, 2014. Pengenalan Sistem Informasi. Yogyakarta

Rosa dan Shalahudin, 2013. Rekayasa Perangkat Lunak Terstruktur dan Berorientasi Objek. Bandung: INFORMARTIKA.

Novera, 2014. Pengaruh Biaya Promosi Terhadap Penjualan Sepeda Motor Honda diCV.Mitra Makmur. Samarinda

Tjandra dan Pickerling, 2015. Aplikasi Metode-Metode Software Testing PadaConfiguration, Compatibility dan Usability Perangkat Lunak. Surabaya

Herdiyansyah, Edi. dkk. 2013.Pengembangan Aplikasi Pendaftaran Muzakki Dan Mustahik Berbasis Web Di Badan Amil Zakat Daerah Kabupaten Garut. Garut

Susanto. 2012. Analisis dan Perancangan Aplikasi E-learning pada SMK 2. Yogyakarta

Tohari. (2014). AnalisaSertaPerancangan SistemInformasi MelaluiUML. Yogyakarta:ANDI.

Nugroho, A.(2010).RekayasaPerangkat Lunak Berorientasi Objekdengan Metode USDP(UnifiedSoftware Development Process). Yogyakarta:PenerbitAndi 
